\title{
Sustainability of an Integrated E-Payment System in Developing Countries
}

\author{
${ }^{1}$ KISSI, PS; *2IDOGA, PE \\ ${ }^{1}$ University of Education Winneba, Department of Management Sciences \\ *2 Federal University Dutse, Cyber Security Department, Nigeria \\ *Corresponding Author Email: dr.pat@fud.edu.ng, Tel: +234 8166744812
}

\begin{abstract}
Over the recent years, there has been tremendous ease in monetary transactions; all thanks to a convenient payment platform. The Integrated e-payment system (IEPS) facilitates financial transactions electronically. This study aims to examine the factorial models necessitating the continuous use of the integrated e-payment system in the light of the Unified Theory of Acceptance and Use of Technology (UTAUT) with two additional variables; processing time and processing charges proposed. The study data were collected from 285 valid respondents in Ghana through the random sampling approach. The hypothesis verification was conducted via the SmartPLS. The result of the structural equation modelling indicate that processing charges, processing time, and social influence are the critical influencers of IEPS continuous usage intention. In addition, it also implies that financial institutions and banks liaise with designers to, perhaps, consider consumers' perspectives in their design; such that will bring about convenience, fast processing and minimal cost in order to foster continuous use.
\end{abstract}

\section{DOI: https://dx.doi.org/10.4314/jasem.v25i8.6}

Copyright: Copyright $\odot 2021$ Kissi and Idoga. This is an open access article distributed under the Creative Commons Attribution License (CCL), which permits unrestricted use, distribution, and reproduction in any medium, provided the original work is properly cited.

Dates: Received: 10 May 2021; Revised: 28 June 2021; Accepted: 01 July 2021

Keywords: Developing Countries, E-payment, Ghana, Intention, UTAUT

The sudden surge in the Internet of things (IoT) coupled with the steady advance in technology has greased the financial sector cumulating in the electronic payment system, thereby enhancing financial transaction processes (Anyanwu et al., 2012). This development has reawakened customer's desires in the utilization of electronic payment system (EPS) for their monetary transactions bearing in mind that issues such as unnecessary charges and prolonged transaction processing time common with the traditional payment system are eliminated in the electronic medium of business transactions. EPS, having been in use for a long time in most countries, this study considered Ghana for two cogent reasons. Firstly, EPS and electronic commerce present good opportunities for emerging countries to build and augment their economic growth (Molla et al., 2006). Secondly, consumers in developing economies cannot yield from the returns of economies of scale and competitive market prospects of old-style market environment. Consequently, opening a window of opportunity that enhances interest in the adoption of EPS. Electronic Payment System (EPS) is the exchange of money over an electronic medium without physical cash or cheque either for the purchase of an item or for services rendered (Kaur and Joshi, 2012). EPS is grouped into five major categories: Prepaid card, electronic cash, credit card, debit card, and electronic cheque. Prior to the deployment of the internet in Ghana, Ghanaian banks relied solely on cash payment for all forms of financial transactions. Recently, electronic payment cum e-payment has continued to realize a steady upward movement, resulting in a devastating reduction in the utilization of the paper-based payment system. This situation, has propelled Ghanaian banks to put all measures in place to catch up with the emergence and speed of the technology (Kwadzo et al., 2018). To this effect, various initiatives on electronic payment have been implemented in Ghana over the years. Some of such initiatives are MTN Mobile Money Transfer, TextnPay and E-Transact (Ametepe et al., 2015). MTN mobile communications is one of the leading telecommunication service providers in Ghana. Although their services have to do with the provision of telecommunication and internet infrastructure, they however, partnered with some major financial institutions in Ghana and launched the mobile money service in July of 2009. The aim of this new service was to provide a convenient payment module for its esteemed customers and the general public, by implementing financial transactions such that has to do with money storage, transfer, as well as the payment of goods and services (Nonor, 2009). The TextnPay system was introduced by the African Xpress in collaboration with other organizations in Ghana to 
provide a secured, convenient mobile money payment system via mobile phones. The system facilitates the sending and receiving of money, payment of bills, procurement of goods and services in addition to purchase of pre-paid airtime, as well as checking of account balance. Furthermore, in addition to the mobile phone payment, the organization has the web based enhanced payment system aiding the free flow of business transactions for both corporate and individual needs (Ametepe et al., 2015). E-Tranzact is another system that facilitates mobile payment via phones. It services includes; payment of bills, airtime purchase, payment of subscriptions, financial services and other services that has to do with payments. Other initiatives at implementing the e-payment system includes the use of automated teller machines (ATM), e-Zwich, personal computer banking, branch networking banking, internet banking, etc. The focus of this study, therefore, is to explore customer's continuous usage intention in the use of the integrated electronic payment system (IEPS). The motivating factor for the study stems from the fact that the usage of IEPS in developing countries often time encounter some challenges that hinders its effective utilization. Hence, the objective of the study is to determine the issues limiting the effective usage of the integrated electronic payment system (IEPS) in Ghana, and propose a framework for improved continuous use employing the Unified Theory of Acceptance and use of Technology (UTAUT).

\section{MATERIALS AND METHODS}

Research design: The study employed the quantitative research approach through the administration of the questionnaire with a five-point Likert-scale measurement. This method of research has been seen to generate a large sample for a subset of the overall population set (Idoga et al., 2019). The questionnaire items were adopted from the studies of Putri (2018) and Örs (2018). Variables in the questionnaire were analyzed to forecast the continuance intention of integrated e-payment system (IEPS). Some variables from the original UTAUT model were used in addition to two external variables.

Measuring tool: The questionnaire constructs were examined to identify the predictors of IEPS continuous usage intention. A five-point Linkert scale extending from $1=$ strongly disagree to $5=$ strongly agree was used for the measurement. The questionnaire was made up of seven sections in order to measure each construct in the model. In the first section, respondent's details such as age and gender were collected. In the second to sixth section, items to measuring Performance expectancy (PE), Effort expectancy (EE), social influence (SI), Processing time (PT) and Processing charges (PC) were included.

Sample and data collection technique: The study population is active customers of a certain financial institution in Ghana. Data collection was conducted from the period of January $27^{\text {th }}-$ February $20^{\text {th }}, 2021$. Using a random sampling method, the questionnaire was distributed to the participant via Google forms. Before the completion of the form, a section of the questionnaire required participants to agree with the consent section before proceeding with the completion of the questionnaire. A total of 483 questionnaires were given out and only 473 respondents were obtained with 188 questionnaires considered invalid; resulting in 285 respondent considered appropriate for further analysis with a response rate of $97.9 \%$.

Statistical analysis: While SPSS 21.0 was applied in the determination of factorial analysis, descriptive statistics and reliability evaluation, Partial Least Square (PLS) via SmartPLS 3.0 was employed for model testing and the examination of the association between latent variables (LV): wherein, hypothesized items were inserted into the dependent constructs of EE, PT, PE, PC, and SI and the independent variable, continuous usage intention ((CUI) figure 1). PLS is a grounded method for analyzing path estimates in structural models and has become progressively prevalent in recent studies (Hair et al., 2013).

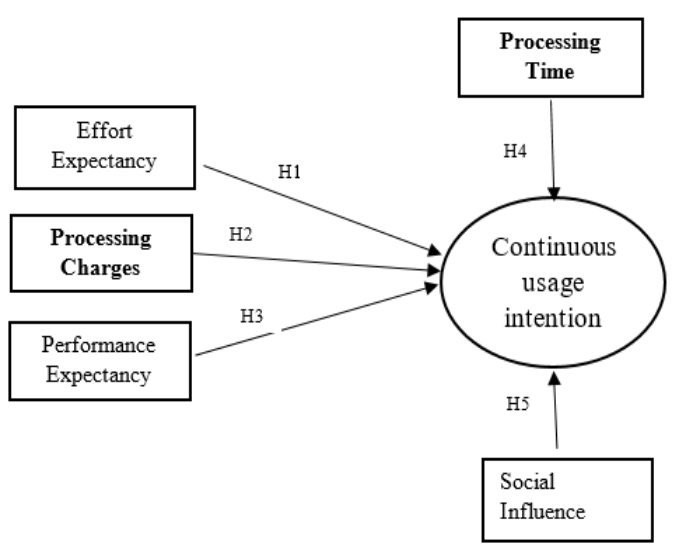

Fig 1: Research Hypothesized Model

The Harman single factor test statistical method was adopted to clarify any issue of common method bias. Interestingly, the procedure exposed that a single factor solution explained $41.446 \%$ of the total variance. This revelation means that, the threshold value of $50 \%$ hasn't been exceeded; indicating that there is no common method bias in the study (Latif et al., 2020). 
In order to validate the study model, a two-step investigative technique recommended for SEM as suggested by (Hair et al., 2016) was used to test the measurement model and the structural model. In addition, the bootstrapping procedure was implemented to examine the loadings and path coefficient significance.

\section{RESULTS AND DISCUSSION}

The relationship between constructs was examined via correlation analysis, and the projectors of IEPS were identified. The table (1) represents the constructs descriptive analysis. The mean of the total constructs signifies a high degree of agreement with CUI (mean $=14.2), \mathrm{EE}($ mean $=11.8), \mathrm{PC}($ mean $=11.3), \mathrm{PE}$ $($ mean $=10.7)$, PT $($ mean $=13.9)$ and SI $($ mean $=14.7)$.

Table 1. Descriptive analysis $(\mathrm{N}=285)$

\begin{tabular}{lll}
\hline Constructs & Mean & $\begin{array}{l}\text { Standard } \\
\text { deviation (SD) }\end{array}$ \\
\hline CUI & 14.22 & 3.16 \\
EE & 11.82 & 3.95 \\
PC & 11.37 & 3.26 \\
PE & 10.77 & 4.27 \\
PT & 13.94 & 3.62 \\
SI & 14.79 & 3.66 \\
\hline \multicolumn{2}{c}{ Reliability and validity }
\end{tabular}

For an adequate measurement to be assured in any evaluation of convergences, 3 important criteria must be fulfilled. One, factor loadings of each construct are utilized in order to examine the reliability of each one of the constructs. Two, either the composite reliability (CR) or the Cronbach's Alpha of each construct is also inspected to ascertain the reliability of each composite material. Third, the Average Variance Extracted (AVE) of each construct evaluated for variance acquired by the construct in relation to the variance due to dimension error (Lin et al., 2019). The table (2) depicts the findings of the reliability and validity evaluation. Evidence can be seen from the table that the constructs satisfied all stipulated benchmarks. Each construct is seen to surpass the fewest yardsticks of 0.5 for factor loadings, 0.7 for composite reliability and 0.5 for AVE. These values indicate a higher CR and a perfect validity for the measurement elucidation (Idoga et al., 2018; Lin et al., 2019). The table 3 illustrates the correlation among indicators and other constructs. According to Fornell and friends, the relationship between indicators in any construct, must be lesser than the square root of the AVEs mutual to indicators of a certain construct (Fornell et al., 1981). As clearly indicated in the diagonal bold prints, the square root of AVEs is larger than other relationships among the constructs; meeting the criteria required for a discriminant validity. Hence, signifying a satisfactory measurement for construct validity (Idoga et al., 2019).

The Fornell and Lacker (1981) study has recently been criticized for inadequacies. Hence the Heterotraitmonotrait (HTMT) ratio suggested by Henseler and friends (2015) was also used to further examine the discriminant validity. The findings from this examination are seen in table 4. As a guiding rule, HTMT is not expected to exceed HTMT.85 (Ali et al., 2016).

\begin{tabular}{|c|c|c|c|c|}
\hline Construct & Indicators & $\begin{array}{l}\text { Factor } \\
\text { Loading }\end{array}$ & CR & AVE \\
\hline \multirow[t]{4}{*}{ CUI } & CUI1 & 0.532 & 0.873 & 0.640 \\
\hline & CUI2 & 0.887 & & \\
\hline & CUI3 & 0.886 & & \\
\hline & CUI4 & 0.840 & & \\
\hline \multirow[t]{4}{*}{$\mathrm{EE}$} & EE1 & 0.792 & 0.867 & 0.619 \\
\hline & EE2 & 0.770 & & \\
\hline & EE3 & 0.816 & & \\
\hline & EE4 & 0.768 & & \\
\hline \multirow[t]{4}{*}{$\mathrm{PC}$} & PC1 & 0.693 & 0.844 & 0.576 \\
\hline & $\mathrm{PC} 2$ & 0.751 & & \\
\hline & PC3 & 0.751 & & \\
\hline & PC4 & 0.833 & & \\
\hline \multirow[t]{4}{*}{ PE } & PE1 & 0.811 & 0.918 & 0.738 \\
\hline & PE2 & 0.889 & & \\
\hline & PE3 & 0.882 & & \\
\hline & PE4 & 0.852 & & \\
\hline \multirow[t]{4}{*}{ PT } & PT1 & 0.665 & 0.900 & 0.695 \\
\hline & PT2 & 0.914 & & \\
\hline & PT3 & 0.885 & & \\
\hline & PT4 & 0.849 & & \\
\hline \multirow[t]{4}{*}{ SI } & SI1 & 0.862 & 0.799 & 0.745 \\
\hline & SI2 & 0.898 & & \\
\hline & SI3 & 0.897 & & \\
\hline & SI4 & 0.790 & & \\
\hline
\end{tabular}

KISSI, PS; IDOGA, PE 
Table 3. Discriminant validity

\begin{tabular}{|c|c|c|c|c|c|c|}
\hline Construct & CUI & EE & PC & PE & PT & SI \\
\hline CUI & 0.796 & & & & & \\
\hline $\mathrm{EE}$ & 0.349 & 0.786 & & & & \\
\hline PC & 0.573 & 0.365 & 0.757 & & & \\
\hline PE & 0.239 & 0.265 & 0.240 & 0.858 & & \\
\hline PT & 0.612 & 0.394 & 0.609 & 0.199 & 0.833 & \\
\hline \multirow[t]{2}{*}{ SI } & 0.472 & 0.287 & 0.333 & 0.150 & 0.641 & 0.863 \\
\hline & Table & Heterot & it-mono & ait (HT) & & \\
\hline Construct & CUI & EE & PC & PE & PT & SI \\
\hline CUI & & & & & & \\
\hline $\mathrm{EE}$ & 0.427 & & & & & \\
\hline $\mathrm{PC}$ & 0.717 & 0.462 & & & & \\
\hline PE & 0.273 & 0.323 & 0.280 & & & \\
\hline PT & 0.735 & 0.476 & 0.731 & 0.233 & & \\
\hline SI & 0.555 & 0.350 & 0.401 & 0.183 & 0.741 & \\
\hline
\end{tabular}

Structural model analysis: Further in the analysis, is the evaluation of the hypothesized association. Straight associations were examined (table 5). Three critical assessments is required for a comprehensive structural model analysis as suggested by Hair et al. (2013). These criteria include: beta, t-values and $\mathrm{R}$ squared. Furtherance to these measurements, it is also necessary for the effect size $\left(\mathrm{f}^{2}\right)$ and predictive significance $\left(Q^{2}\right)$ to be reported. From the table (6), the findings for IEPS continuous usage intention indicate that, apart from $\mathrm{EE} \rightarrow \mathrm{CUI}(\beta=0.060, \mathrm{t}=1.124, \mathrm{p}=$ $0.262)$ and $\mathrm{PE} \rightarrow \mathrm{CUI}(\beta=0.069, \mathrm{t}=1.568, \mathrm{p}=0.117)$, every other hypothesis were substantial. Hence, the hypothesis $\mathrm{H} 2, \mathrm{H} 4$ and $\mathrm{H} 5$ are supported, whereas the hypothesis $\mathrm{H} 1$ and $\mathrm{H} 3$ are not supported. Moreover, CUI accounted for $46.3 \%$ of variance $\left(R^{2}=0.463\right)$. This $R^{2}$ value is higher than the 0.26 value suggested by Cohen (1988) as an indication for a significant model. The effect size $\left(\mathrm{f}^{2}\right)$ was assessed next. Cohen (1988) presented some guidelines for the adequate measurement of $\mathrm{f}^{2}$. According to him, a value of 0.02 is considered a small effect, 0.15 a medium effect, and 0.35 a large effect. The table (5) shows the $\mathrm{f}^{2}$ of this study with the H1, H3, H4 and H5 seen to have a small effect, while the $\mathrm{H} 2$ has a medium effect. Furthermore, the sample reuse technique based on the method of Blindfolding was employed to show the predictive relevance $\left(\mathrm{Q}^{2}\right)$ of the model. Accordingly, a $\mathrm{Q}^{2}<0$ indicate a poor model. Hence no predictive relevance. However, a $\mathrm{Q}^{2}>0$ signifies that the model possesses a predictive relevance. In this study, the $\mathrm{Q}^{2}$ for exogenous and endogenous variables connotes a satisfactory predictive relevance of 0.268.

Table 5. Hypotheses testing

\begin{tabular}{lllll}
\hline Hypotheses & Beta & T-values & Decision & $\mathrm{F}^{2}$ \\
\hline $\mathrm{H} 1: \mathrm{EE} \rightarrow$ CUI & 0.060 & 1.124 & Not supported & 0.005 \\
$\mathrm{H} 2: \mathrm{PC} \rightarrow$ CUI & 0.308 & $4.928^{* *}$ & Supported & 0.105 \\
$\mathrm{H} 3: \mathrm{PE} \rightarrow$ CUI & 0.069 & 1.568 & Not supported & 0.008 \\
$\mathrm{H} 4: \mathrm{PT} \rightarrow$ CUI & 0.285 & $3.810^{* *}$ & Supported & 0.061 \\
$\mathrm{H} 5: \mathrm{SI} \rightarrow$ CUI & 0.159 & $2.505^{* *}$ & Supported & 0.027 \\
\hline \multicolumn{4}{c}{ Note: critical t-values. } & 1.96 $(\mathrm{P}<0.05) ; * * 2.58(\mathrm{P}<0.01)$
\end{tabular}




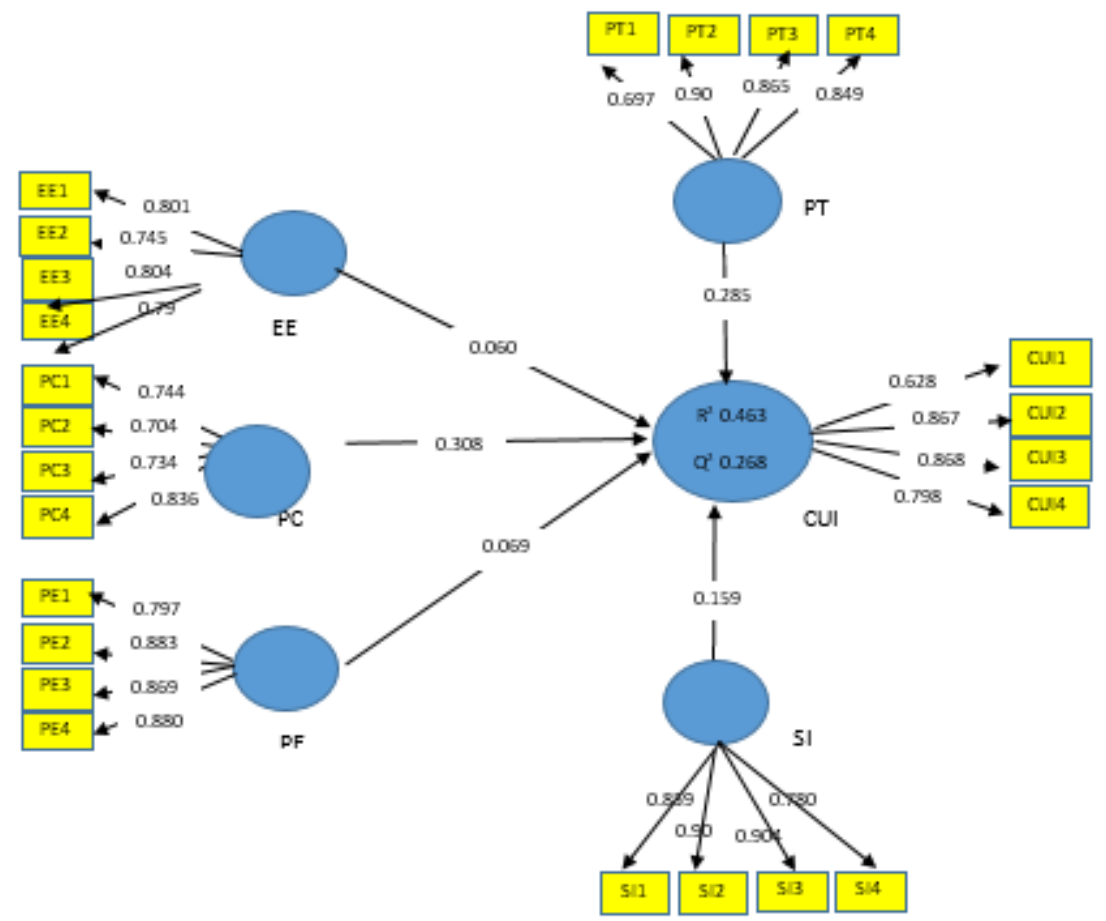

Fig 2: Structural model

The study examined the continuous usage intention of the integrated e-payment system (IEPS) by expanding the Unified Theory of Acceptance and use of Technology (UTAUT) and by the exploration of direct impact via effort expectancy (EE), processing charges (PC), performance expectancy (PE), processing time (PT) and social influence (SI) in Ghana. The study's findings depict a substantial positive association between PC and CUI, PT and CUI, and SI and CUI; validating earlier research studies (De Sena et al., 2016; Możdżyński, 2018). This revelation is a confirmation to the theory of social identity in which it is contended that customers will often associate themselves with organizations that has impact on their social identity. Consequently, when bank customers assess their option of banking products/services importance might be given to these areas (Latif et al., 2020). Surprisingly, of the five hypotheses postulated, only effort expectancy (H1) and performance expectancy (H3) were found not to be associated with the continuance usage intention of IEPS. This discovery aligns with the study of Gouveia and Coelho, (2007) where effort expectancy was seen to be negative. Therefore, three hypotheses from this study, processing charges $(\mathrm{H} 2)$, processing time $(\mathrm{H} 4)$ and social influence (H5) are revealed to be the predictors of integrated e-payment systems (IEPS) continuous usage intention. Generally, the constructs processing charges, processing time, and social influence explained $46.3 \%$ predictive power of the continuous usage intention of IEPS. This study contributes to the body of knowledge from three perspectives. Firstly, in terms of the theoretical contributions, the study provides empirical support for the need to consider the processing time and processing charges associated with IEPS delivery. Accordingly, the social identity of IEPS to users is another vital revelation. Consequently, enhancing the development of an improved comprehension of the channel of impact of PT, PC and SI on CUI, is the major theoretic contribution of this study. Secondly, in terms of managerial perspective, the study findings revealed that UTAUT is adequate in measuring the effect of influencing constructs which directly impact the customer's continuous usage intention of IEPS. Our findings bare that UTAUT has sizeable effect on PC. Hence, financial institutions in Ghana should make effort to minimize charges on IEPS platforms. Thirdly, the study findings are of academic benefits in that; it collates the same model of continuous usage intention some familiar constructs applicable in contemporary researches to forecast the continuous usage intention from the perspective of Ghanaian IEPS users. Consequently, the scheme of a novel prototype for disparate setting. This study is limited in some ways. In the first instance, the study emphasized on the performance expectancy, effort expectancy, social influence, processing time and processing charges of IEPS for the continuous usage intention. A crossintuitive designed measures of such could lead to method bias. In the second instance, the study is limited by the sample size; hence, generalization of the 
study findings is problematic. In addition, considering that the study sample was drawn from just one bank, it is possible for bias to take place. Therefore, evaluating with more different bank customers may enhance the development of a more robust model adequate for generalization. We hope to extend this study to a cross country analysis in our future studies where disparate constructs such as cultural differences with large sample size will be examined.

Conclusion: This empirical study added a novel study outline to the continuous usage intention of the IEPS in Ghana. The modified framework for this study is the UTAUT framework with two additional concepts. The experiential findings from this research propose that processing charges, processing time and social influence are critical influencers of customer's CUI of an IEPS. The study findings clearly imply that banks and financial institutions will benefit greatly from the outcome of this research. In addition, it also implies that financial institutions liaise with designers to perhaps, consider consumer's perspectives in their design.

Acknowledgments: The authors are grateful to the financial institution which provided access for data gathering and to all the participants who granted us audience. There was no funding for this research, and the authors declare that there is no conflict of interest.

\section{REFERENCES}

Ali, F; Kim, WG; Ryu, K (2016). The effect of physical environment on passenger delight and satisfaction: Moderating effect of national identity. Touri. Manage. 57, 213-224.

Ametepe-MW; Abdullai, D; Annan, NK (2015). Examining Issues of Electronic Payment Systems in Ghana. Inform. Knowl. Manage. 5 (5)

Anyanwu, AC; Ezugwu, AE; Abdullahi, SE (2012). Electronic payment system (EPS): facilitating the development and adoption in Nigeria. Int. J. of Comp. Sci. Iss. (IJCSI), 9(2), 462.

Cohen, J (2013). Statistical power analysis for the behavioural sciences. Academic press.

De Sena, AR; Moriguchi, SN; Andrade, DF (2016). Intention of adoption of mobile payment: An analysis in the light of the Unified Theory of Acceptance and Use of Technology (UTAUT). RAI Revista de Administração $e$ Inovação, 13(3), 221-230.
Fornell, C; Larcker, DF (1981). Evaluating structural equation models with unobservable variables and measurement error. J. Mark. Res. 1981, 18, 3947. [CrossRef]

Gouveia, JM; Coelho, AFM (2007). Determinates da adopçao de novas tecnologias de informaçao e comunicaçao o caso da internet móvel em Portugal. In Conocimiento, innovación $y$ emprendedores: camino al futuro (p. 153). Universidad de La Rioja.

Hair Jr, JF; Hult, GTM; Ringle, C; Sarstedt, M (2016). A primer on partial least squares structural equation modeling (PLS-SEM). Sage publications.

Hair, JF; Ringle, CM; Sarstedt, M (2013). Partial least squares structural equation modeling: Rigorous applications, better results and higher acceptance. Long rang. plan. 46(1-2), 1-12.

Henseler, J; Ringle, CM; Sarstedt, M (2015). A new criterion for assessing discriminant validity in variance-based structural equation modeling. J. of the Aca. Mark. Sci. 43(1), 115-135.

Idoga, PE; Toycan, M; Nadiri, H; Çelebi, E (2018). Factors affecting the successful adoption of ehealth cloud based health system from healthcare consumers' perspective. IEEE Access, 6, 7121671228 .

Idoga, PE; Toycan, M; Nadiri, H; Çelebi, E (2019). Assessing factors militating against the acceptance and successful implementation of a cloud based health center from the healthcare professionals' perspective: a survey of hospitals in Benue state, northcentral Nigeria. BMC med. Inform. and deci. Mak. 19(1), 34.

Kaur, P; Joshi, MM (2012). E-commerce in india: A review. IJCST, 3(1), 802-804.

Kwadzo, FA; Adroe, RK; Asante, M (2018). Analysis of Electronic Payment Systems in Ghana-A Case Study of Mobile Payment System. Int. J. of Sci. Res. and Manage. 6(06).

Latif, KF; Pérez, A; Sahibzada, UF (2020). Corporate social responsibility (CSR) and customer loyalty in the hotel industry: A cross-country study. Int. J. of Hosp. Manage. 89, 102565.

Lin, X; Wu, R; Lim, YT; Han, J; Chen, SC (2019). Understanding the sustainable usage intention of 
mobile payment technology in Korea: crosscountries comparison of Chinese and Korean Users. Sustain. 11(19), 5532.

Molla, A; Taylor, R; Licker, PS (2006). E-commerce diffusion in small Island countries: the influence of institutions in Barbados. The Elect. J. of Infor. Syst. in Dev. Count. 28(1), 1-15.

Możdżyński, D (2018). Acceptance of payment systems from the perspective of merchants. Infor. Sys. in Manage. 7.
Nonor, D (2009), MTN Introduces MTN Mobile Money Banking, The Ghan. J. July 24th, 2009, http://www.theghanaianjournal.com/, Date accessed: 12/06/19.

Örs, ME (2018). Development of a Technology Acceptance Model for Mobile Payment Systems. The Mid. East Tech. Uni. Master Thesis.

Putri, DA (2018, May). Analyzing Factors Influencing Continuance Intention of E-Payment Adoption Using Modified UTAUT 2 Model. In 2018 6th International Conference on Information and Communication Technology (ICoICT) (pp. 167173). IEEE. 